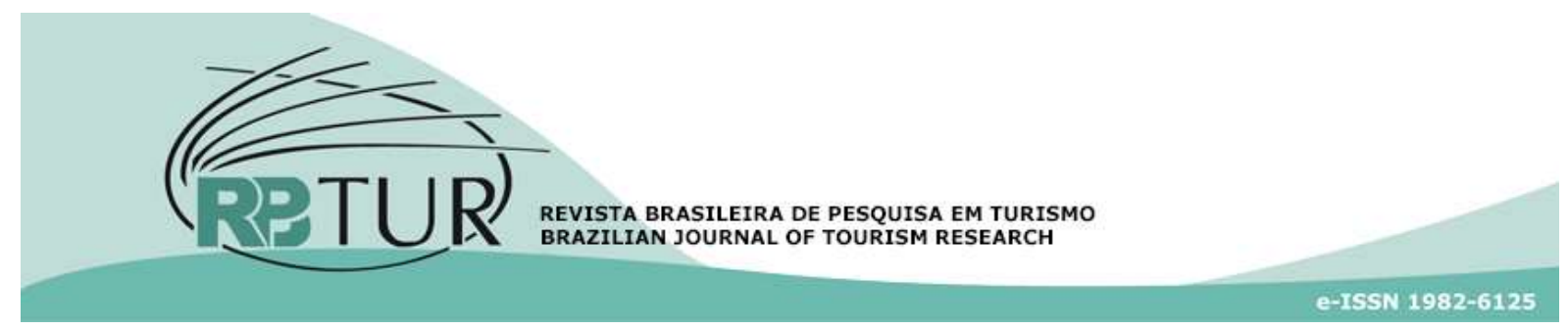

Artigo

DOI: http://dx.doi.org/10.7784/rbtur.v12i2.1415

\title{
Governança do Turismo no Campo das Vertentes (MG): garantia de desenvolvimento regional?
}

\author{
Governance of Tourism in Campo das Vertentes, MG, Brazil: a path \\ to regional development?
}

\section{Gobernanza del Turismo en el Campo das Vertentes (MG): garantía de desarrollo regional?}

\section{Thiago de Sousa Santos ${ }^{1}$ Raquel da Silva Pereira ${ }^{2}$}

Resumo: O objetivo deste estudo é verificar o papel e a articulação dos órgãos de governança nas ações de turismo desenvolvidas na região Campo das Vertentes, em Minas Gerais. Para tanto, foram investigados os municípios de Prados, São João Del Rei e Tiradentes, pertencentes ao Circuito Turístico Trilha dos Inconfidentes. Como base teórica foram considerados os dez elementos de governança propostos por Bovaird e Löffler (2003). A de natureza qualitativa foi do tipo exploratória. Utilizou-se pesquisa documental, além da realização de 12 entrevistas em profundidade. Os resultados a existência de um nível bastante avançado de governança no desenvolvimento da região, mesmo havendo discrepâncias de níveis de governança entre os municípios analisados. Constatou-se que o Circuito Turístico Trilha dos Inconfidentes, responsável por estabelecer um canal direto com o poder público na esfera estadual e federal em prol de necessidades da região, possui relevante poder e influência sobre as ações, projetos e programas realizados.

\footnotetext{
${ }^{1}$ Doutor em Administração pela Universidade Municipal de São Caetano do Sul (USCS). Professor do Instituto Federal de Educação, Ciência e Tecnologia do Sul de Minas Gerais (IFSULDEMINAS). O artigo desenvolvido é parte da tese de doutorado desenvolvida no Programa de Pós-graduação em Administração da Universidade Municipal de São Caetano do Sul. Responsável pelaestruturação do artigo, levantamento e construção do referencial teórico, desenvolvimento da metodologia e instrumentos, pesquisa de campo, coleta de dados e análise no Atlas TI.

2 Doutora em Ciências Sociais pela Pontifícia Universidade Católica de São Paulo (PUC/SP). Professora, Pesquisadora e Gestora do Programa de Pós-graduação em Administração da Universidade Municipal de São Caetano do Sul (PPGA/USCS). Atuou como orientadora do Dr. Thiago de Sousa Santos durante todo o período de doutorado no Programa de Pós-graduação em Administração da Universidade Municipal de São Caetano do Sul. Contribuiu na estruturação do projeto de pesquisa, no referencial teórico, na análise de dados e conclusão do artigo.
}

Artigo recebido em: 07/02/2018. Artigo aceito em: 18/04/2018.

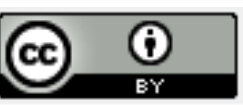


Palavras-chave: Turismo. Governança. Desenvolvimento Regional. Campo das Vertentes. Trilha dos Inconfidentes.

\begin{abstract}
The purpose of this study is to verify coordination and the role of governance structures in tourism activities in the region of Campo das Vertentes, state of Minas Gerais. For that, we studied the municipalities of Prados, São João Del Rei, and Tiradentes, included in the "Trilha dos Inconfidentes" ('Inconfidentes' trail). As a theoretical basis, the ten elements of governance proposed by Bovaird and Löffler (2003) were considered. This study is exploratory and of a qualitative nature. We used documentary research and conducted 12 in-depth interviews. The results show a high level of governance development in the region, even though there are discrepancies between the municipalities analyzed. It was verified that the Tourist Circuit "Trilha dos Inconfidentes", responsible for establishing a direct channel with the public power at the state and federal levels in order to meet the needs of the region, has relevant power and influence over the actions, projects, and programs that are carried out.
\end{abstract}

Keywords: Tourism. Governance. Regional development. Campo das Vertentes. Trilha dos Inconfidentes.

Resumen: El objetivo de este estudio es verificar el papel y la articulación de los órganos de gobernanza en las acciones de turismo desarrolladas en la región Campo das Vertentes, en Minas Gerais. Para ello, fueron investigados los municipios de Prados, São João Del Rei y Tiradentes, pertenecientes al Circuito Turístico Pista de los Inconfidentes. Como base teórica se consideraron los diez elementos de gobernanza propuestos por Bovaird y Löffler (2003). La de naturaleza cualitativa fue del tipo exploratoria. Se utilizó investigación documental, además de la realización de 12 entrevistas en profundidad. Los resultados de la existencia de un nivel bastante avanzado de gobernanza en el desarrollo de la región, aun habiendo discrepancias de niveles de gobernanza entre los municipios analizados. Se constató que el Circuito Turístico Trilha de los Inconfidentes, responsable de establecer un canal directo con el poder público en la esfera estadual y federal en favor de las necesidades de la región, posee relevante poder e influencia sobre las acciones, proyectos y programas realizados.

Palabras clave: Turismo. Gobernanza. Desarrollo Regional. Campo das Vertentes. Trilha dos Inconfidentes.

\section{INTRODUÇÃO}

A valorização do regional como contraponto ao global, vem contribuindo para que se discutam, com ênfase cada vez maior, questões de natureza conceitual e teórica relativas à região, ao regionalismo e a regionalidade (Gil, Oliva, \& Silva, 2009). Nesse sentido, como fator de desenvolvimento econômico, o turismo pode gerar aumento e redistribuição de renda por meio da comercialização de bens e serviços consumidos por turistas. Como fator de desenvolvimento social, a atividade turística pode contribuir com o aumento de empregos diretos e indiretos, mantendo a proteção e preservação do patrimônio histórico-cultural e ambiental (Silveira, 2008).
O Conselho Mundial de Viagens e Turismo - World Travel \& Tourism Council (WTTC), divulga em relatórios anuais uma análise sobre a contribuição do setor de viagens e turismo para a economia global. Em 2013, tal contribuição foi de 9,5\% do PIB global, elevando para 9,8\% em 2014 e 2015 e chegando a 10,2\% em 2016, quando o setor gerou 7,6 trilhões de dólares em todo 0 mundo e contribuiu para um total de $292 \mathrm{mi}$ Ihões de empregos, sendo um a cada dez, de todos os empregos computados. De acordo com a Organização Mundial de Turismo OMT (2017), o deslocamento internacional de turistas teve aumento significativo ao longo do tempo, passando de 25 milhões em 1950 para 1.235 milhões em 2016.

O turismo é um fenômeno que movi- 
menta milhões de pessoas no mundo todo, assumindo-se como um dos principais motores da economia global (Sousa, 2016). Destaca-se que, conforme dados da OMT, desde 2009, após a crise financeira mundial, 2016 foi o sétimo ano consecutivo de crescimento. No Brasil, o setor apresentou uma contribuição total - que inclui as atividades diretas, indiretas e induzidas do turismo - de 9,2\% do PIB, o equivalente a US\$ 205,6 bilhões. Dentre a lista das maiores economias do turismo no mundo, os Estados Unidos lideram com cerca de US\$ 1,4 trilhões. O Brasil aparece em sexto lugar. Isto demonstra que a atividade é rentável e competitiva, e que, se planejada adequadamente, pode contribuir para o desenvolvimento sustentável dos municípios de uma determinada região (Molina, 2005; WTTC, 2016).

O turismo, uma atividade que pressupõe determinado nível de estrutura organizacional fundamentada nas necessidades e nas motivações manifestadas pelos atores envolvidos, requer uma série de ações voltadas ao atendimento dos requisitos da oferta e das exigências da demanda. Tais ações, por sua vez, necessitam ser ordenadas em decisões pautadas em políticas públicas para o setor, as quais carecem de governança institucionalizada da atividade turística capaz de defini-las e implementá-las com legitimidade (Dreher \& Salini, 2010). Ao poder público cabe prover infraestrutura básica, sensibilizar atores, promover destinos, regulamentar a atividade e especialmente, planejar, estabelecendo objetivos, metas e diretrizes macro, tendo em vista o desenvolvimento amplo da atividade no território (Minas Gerais, 2014).
No Brasil, o Ministério do Turismo lançou o Plano Nacional de Turismo - PNT 2003-2007, no qual o turismo passou a ser considerado uma das dez áreas prioritárias (Brasil, 2007a). Entre as diretrizes do Plano, consta o incentivo à organização de roteiros integrados, de consórcios intermunicipais, além da proposta de regionalização, como forma de ampliar as opções ao turista com municípios atuando de maneira integrada e complementar.

Com a revisão do PNT 2003-2007, novas propostas foram incluídas ao PNT 20072010, surgindo, assim, um novo ator, os circuitos turísticos, responsáveis pela coordenação regional da atividade, contemplando as instâncias de governança regional. Neste contexto, a região passa a ser o foco do planejamento e deixa-se de discutir a ação municipal independente, ou seja, os municípios passam a fazer parte de um contexto maior que é a região, configurando um grande avanço para o setor e para o desenvolvimento regional (Brasil, 2009).

Alinhado ao Programa de Regionalização do Turismo - PRT, em 2003, a Secretaria de Turismo do Estado de Minas Gerais SETUR, publica o decreto no 43.321 que dispõe sobre o reconhecimento dos Circuitos Turísticos institucionalizados e com personalidade jurídica própria. Desde então, as ações previstas nos Planos Plurianuais de Ação Governamental contemplam a regionalização do turismo em Minas Gerais por meio dos Circuitos Turísticos.

Na região escolhida para o estudo, denominada Campo da Vertentes, são 22 os municípios que compõem o Circuito Turístico Trilha dos Inconfidentes - CTTI, que leva este 
nome porque, dos 23 inconfidentes mineiros, nove residiram na Comarca do Rio das Mortes, cuja sede era a Vila de São João Del Rei. Cortado pela Estrada Real, por onde passaram os primeiros colonizadores e os libertários comandados por Tiradentes, este é um Circuito de vasta riqueza cultural, natural, histórica e patrimonial (Oliveira \& Januário, 2007; CTTI, 2010). Essa região foi escolhida por ter na atividade turística uma importante fonte de renda e ocupação para seus munícipes, conforme afirmam Oliveira e Januário (2007), Neves e Carneiro (2014) e Rodrigues, Silva e Diniz (2012). Dentre os municípios que compõem a Mesorregião Campo das Vertentes e que fazem parte do Circuito Turístico Estrada Real, criado para impulsionar o desenvolvimento regional, destacam-se economicamente os municípios de Prados, São João Del Rei e Tiradentes, economia essa gerada a partir de turismo e artesanato, razão de terem sido escolhidos para este estudo, em detrimento de outros municípios da região.

O município de Prados destaca-se por possuir características culturais e históricas com arquitetura barroca datada dos séculos XVIII e XIX, pela tradição das festas religiosas, pela produção artesanal. São João Del Rei, por ser um destino indutor em nível estadual, e Tiradentes, por ser um destino indutor em nível nacional. Esses três municípios são os que mais se destacam pela atividade turística na região (Silveira, 2008; Rodrigues, Silva \& Diniz, 2012; Neves \& Carneiro, 2014).

No ano 2000, foi fundado CTTI supracitado, entidade civil de direito privado, sem fins lucrativos, que possibilitaria aos municípios atenderem a Lei Estadual no 13.341 (1999), a qual estabelece que os municípios se articulem de forma regionalizada para o planejamento participativo do turismo. (CTTI, 2010).

De acordo com a SETUR (2015), a região do Campo das Vertentes teve um aumento de $53,2 \%$ no número de estabelecimentos de hospedagem em Minas Gerais, entre 2006 a 2014. Taxa de variação maior que em outras regiões mineiras, tais como a Sul, a Metropolitana e a de Belo Horizonte, que possuem os maiores números de estabelecimentos do setor de hospedagem no referido Estado (Minas Gerais, 2015).

Diante do exposto, identificar como se dá a governança e verificar o papel e a articulação dos órgãos envolvidos nas ações de turismo torna-se relevante para melhor compreender como se assegura o desenvolvimento da atividade turística na região.

\section{DESENVOLVIMENTO REGIONAL}

Pike, Rodríguez-Pose e Tomaney (2007, p.1263) afirmam que um dos atuais entendimentos de desenvolvimento é "o estabelecimento de condições e instituições que promovam a realização do potencial das capacidades e faculdades da mente humana em pessoas, comunidades e (...) lugares ". Considerando tal contexto, a importância crescente da análise sobre desenvolvimento regional encontra-se, atualmente, em diversos estudos, tanto em âmbito nacional quanto internacional (Alcade, Le Bourlegat \& Castilho, 2007; Tomazzoni, 2007).

De acordo com Bassan e Siedenberg (2008) uma região é representada por características relacionadas à: (1) formação geomorfológica, econômico-social, histórica e cultural; (2) distribuição espacial da popula- 
ção; (3) origens do processo produtivo; (4) base econômica local; (5) aspectos políticos; e (6) aspectos administrativos.

Boisier (1996, p. 33) destaca que desenvolvimento Regional resulta de "um processo de mudança sustentada que tem como finalidade última o progresso permanente da região, da comunidade regional como um todo e de cada indivíduo residente nela".

Conforme Dallabrida e Becker (2008), desenvolvimento regional refere-se a um determinado processo de territorialização que contempla a dimensão da reterritorialização, capaz de estimular as potencialidades e contribuir para a superação dos desafios locais/regionais, que privilegie a dimensão da inclusividade ou não liberdades. Os autores ainda complementam destacando que o desenvolvimento regional necessita ser capaz de promover os agentes regionais à condição de sujeitos que envolva os territorializados, os que estão em processo de desterritorialização e os já desterritorializados, potencializando sua capacidade de auto-organização, implementando uma dinâmica territorial do desenvolvimento mais autônoma, não privatista, menos desigual e segundo a lógica da sociedade.

Carniello e Santos (2013) destacam que os estudos sobre desenvolvimento regional demandam, necessariamente, uma perspectiva interdisciplinar. Neste sentido, a contribuição das distintas áreas do conhecimento foi se delineando paulatinamente, consolidando conceitualmente de forma clara, os paradigmas que pautam estudos contemporâneos, de forma a superar a inicial disciplinaridade da Economia, área de gênese das discussões sobre o desenvolvimen- mento em âmbito acadêmico. Destacando a representatividade dessa área, ressalta-se, inclusive, a impossibilidade de se pensar desenvolvimento regional sem a perspectiva econômica, os ângulos de reflexão foram se ampliando e extrapolando os limites de um único campo do conhecimento.

Considerando tais perspectivas, abordar o tema esenvolvimento Regional e Turismo vem ganhando destaque na pesquisa científica mundial (Tomazzoni, 2007; Gil, Oliva \& Silva, 2009; Lohmann \& Dredge, 2012).

\subsection{Turismo}

Em 1911, Hermann von Schullern zu Schattenhofen escreveu que "turismo compreende todos os processos, especialmente os econômicos, que se manifestam na chegada, na permanência e na saída do turista de um determinado local" (apud Wahab, 1991, p. 48). Esta definição focada na economia explica-se pelo fato de o autor ser economista (Santos, Souza \& Pereira, 2014).

$O$ conceito de turismo é muito abrangente, não existindo um único conceito aceito internacionalmente, uma vez que apresenta diversas concepções relacionadas com a abordagem de cada autor (Souza, 2012). Na definição apresentada, nota-se, as seguintes variáveis: tempo de permanência; a visita sem fins lucrativos e a livre escolha. Além das variáveis, têm-se os elementos que compõem esta atividade intangível, que são: os turistas; a história; a cultura; o espaço geográfico e os negócios e instituições (Santos, Souza \& Pereira, 2014).

O turismo tem sido visto em muitos 
lugares, sobretudo nas cidades históricas, como o meio mais fácil e rápido para o desenvolvimento econômico e, em alguns casos, como o único meio. Cabe aos agentes de desenvolvimento turístico discutirem e decidirem como deve ser esse desenvolvimento e o que estão dispostos a fazer para melhorar a atividade para que ocorra ganho e não perda na qualidade de vida local (Silveira, 2008). Neste sentido, considera-se como papel da administração pública, juntamente com a comunidade local, apontar possíveis ações para o seu melhor funcionamento. Girard e Nijkamp (2009, p.20) destacam que "o turismo se tornou um setor global com amplo e significativo impacto no resultado social e econômico no desenvolvimento de nações e regiões".

Brida, Riaño, Devesa e Zapata-Aguirre (2012), destacam que o apoio da população local para o desenvolvimento do turismo é essencial, sobretudo para se obter sucesso em qualquer processo de planejamento da atividade turística, inclusive porque o desenvolvimento do turismo implica em impactos, tanto positivos como negativos. Tais impactos variam desde mudanças nas estruturas sociais e econômicas e no meio cultural, até efeitos ambientais (Widmer, Pereira \& Melo, 2008).

Outro aspecto a se considerar é a arte popular criativa, como oferta complementar ao produto "turismo cultural" em espaço urbano. Trata-se de uma atividade social e econômica relevante, numa lógica de renovação de territórios culturais, de arranjos dos espaços públicos, de valorização e requalificação de bairros ou setores particulares das cidades. As contribuições dessa arte popular criativa para os núcleos urbanos turísticos estão associadas à criação de melhores condições de vida para os artesãos tradicionais e contemporâneos do lugar, uma vez que geram oportunidades de trabalho e renda (Santos \& Silva, 2016).

Em algumas regiões, pode-se observar paisagens, territórios, lugares e cidades turísticas, em que há um visitante bem informado e atento, que deseja observar e adquirir produtos artísticos de origem artesanal, que representem a cultura local, feitos por mãos hábeis que obedecem a intuição do artista. Esse turista sinais de identidade e particularidades que não são globais, valorizando a singularidade local e o turismo cultural. Assim, a arte popular torna-se complemento ao turismo cultural, contribuindo com o desenvolvimento econômico e social. Ressalta-se que em meios urbanos, como no caso de Loulé, no Algarve português, pode-se observar um produto turístico específico, cheio de particularidades e com grandes potencialidades (Santos \& Silva, 2016).

Segundo Santos e Silva (2016), o artesanato não se enquadra em uma linearidade cultural, uma vez que supera a barreira do local e envolve uma rede de outros atores participantes do turismo cultural regional, tronando-se parte do destino turístico regional.

A tradição se manifesta por meio de valores, crenças e rituais transmitidos e conservados de geração em geração. O trabalho do artesão é uma tradição popular que deve ser analisada em seu contexto local, pois é um elemento constitutivo da cultura, paisagem e das relações de aprendizado em diferentes contextos, locais e regionais. De acordo com os interesses de órgãos públicos e privados, pode-se tornar um componente cultural do turismo urbano (Santos \& Silva, 
2016).

Grande parte das viagens é realizada para destinos que dispõem de fatores culturais notáveis, tais como os locais históricos, monumentos, centros arqueológicos, centros de peregrinação,

concentrações de caráter étnico, arte oleira, entre outros. Alguns desses fatores podem ser criados artificialmente em qualquer parte (caso dos museus), mas outros estão profundamente ligados aos locais onde se desenvolveram (locais históricos ou centros arqueológicos, por exemplo), e há ainda aqueles que se relacionam à maneira de viver de cada povo, como os saberes tradicionais por meio de obras artesanais, com uma abordagem integrada à arte popular (Santos \& Silva, 2016, p. 218).

Cunha e Cunha (2005) destacam que o Brasil, ao aliar-se ao processo de globalização do turismo, adota as normas da OMT, para quem a lógica está calcada no processo de sensibilização, conscientização, interiorização e sustentabilidade do turismo, de forma a promover o planejamento regional integrado, envolvendo assim, os autóctones no processo.

O planejamento formal do turismo por parte do Estado tem seus antecedentes na França, na década de 1940, com a elaboração do Primeiro Plano Quinquenal do Equipamento Turístico (Pereira, 1999). A partir da década de 1960, o planejamento da atividade tornou-se mais comum nos países europeus. A princípio, os planos de turismo tinham um enfoque urbanístico, atentando apenas para a criação de infraestrutura e planejamento e uso do solo (Pereira, 1999; Gomes, 2007).

Silva e Passador (2016) afirmam que, entre as diversas possibilidades de políticas descentralizadoras, é possível destacar que a promoção do turismo é responsabilidade compartilhada pela União, estados e municípios. Neste contexto, considera-se que o planejamento e a colaboração descentralizada, seguindo uma corrente regionalista, tendem a aumentar a capacidade do turismo em gerar bem-estar para as comunidades (Shone \& Memon, 2008).

Para Souza, Pena e Moesch (2017), a identificação, formação, construção e operacionalização de ecossistemas ou aglomerados implicados pela atividade turística em sua dimensão regional conformam-se, na maioria dos casos, pelas políticas públicas iniciadas com tais propósitos.

Por meio de uma estruturada de rede de governança, a política pública do turismo é executada de forma regionalizada, organizada e descentralizada, articulando-se com as Associações de Circuitos Turísticos, respeitando o mosaico cultural e natural, evidenciando o Estado de Minas Gerais, com 447 municípios (Minas Gerais, 2015).

\subsection{Governança}

A governança pressupõe questões diretamente relacionadas, tais como a descentralização das decisões políticas e o ganho de poder pela sociedade para participar nos processos de tomada de decisão (Stoker, 1998). A governança pode e deve apoiar e incentivar o Desenvolvimento Regional (Paixão, 2013).

Bovaird e Löffler (2003) listam dez elementos (ou categorias) da boa governança. Alguns outros elementos também são apontados pelo Word Bank (1992) e pela International Federation of Accountants - IFAC 
(2001), junto a outros autores, o que fortalece a prática da governança como instru- mento de gestão, incluindo a gestão do turismo.

Quadro 1 - Elementos de governança

\begin{tabular}{|c|c|}
\hline ELEMENTOS & CARACTERÍSTICAS DAS CATEGORIAS \\
\hline $\begin{array}{l}\text { Envolvimento dos Cidadãos } \\
\text { World Bank (1992, p. 40); Bovaird } \\
\text { e Löffler }(2003, \text { p. } 322) .\end{array}$ & $\begin{array}{l}\text { Participação da população no planejamento dos projetos e ações de tu- } \\
\text { rismo. Participação da população em decisões significativas. }\end{array}$ \\
\hline $\begin{array}{l}\text { Transparência } \\
\text { World Bank (1992, p. 40); IFAC } \\
\text { (2001); Bovaird e Löffler (2003, p. } \\
\text { 322). }\end{array}$ & $\begin{array}{l}\text { Como é feita a divulgação dos projetos; todos os atores envolvidos têm } \\
\text { acesso às informações e resultados dos programas desenvolvidos. Os im- } \\
\text { pactos são de conhecimento de todos os stakeholders. Transparência na } \\
\text { tomada de decisões. }\end{array}$ \\
\hline $\begin{array}{l}\text { Prestação de contas } \\
\text { IFAC (2001); Bovaird e Löffler } \\
(2003, \text { p. } 322) \text {. }\end{array}$ & $\begin{array}{l}\text { Existe um modelo de prestação de contas profissional; responsabilidade } \\
\text { da prestação de contas; qualidade das informações na prestação de con- } \\
\text { tas. }\end{array}$ \\
\hline $\begin{array}{l}\text { Agenda de Igualdade e inclusão } \\
\text { Bovaird e Löffler (2003, p. 322). }\end{array}$ & $\begin{array}{l}\text { Nível de desigualdade de renda na região. Existência de uma agenda que } \\
\text { contenha ações que promovem igualdade e inclusão social (acesso à mo- } \\
\text { radia, segurança pública, educação). }\end{array}$ \\
\hline $\begin{array}{l}\text { Comportamento ético e honesto } \\
\text { IFAC (2001); Bovaird e Löffler } \\
(2003, \text { p. 322).; Barret (2003). }\end{array}$ & $\begin{array}{l}\text { Nível de compromisso, responsabilidade e senso de justiça na gestão das } \\
\text { instituições; existência de código de ética. }\end{array}$ \\
\hline $\begin{array}{l}\text { Capital (procedimentos justos e } \\
\text { processo legal) } \\
\text { WORLD BANK (1992, p. 40); } \\
\text { Bovaird e Löffler (2003, p. 322). }\end{array}$ & $\begin{array}{l}\text { Estrutura e procedimentos justos e equilibrados na alocação de recursos } \\
\text { financeiros. }\end{array}$ \\
\hline $\begin{array}{l}\text { Capacidade de competir em um } \\
\text { ambiente global } \\
\text { Bovaird e Löffler (2003, p. 322). }\end{array}$ & Nível de competitividade; mercados explorados. \\
\hline $\begin{array}{l}\text { Capacidade de trabalhar eficaz- } \\
\text { mente em parceria } \\
\text { Bovaird e Löffler (2003, p. 322). }\end{array}$ & $\begin{array}{l}\text { Nível de cooperação na busca de objetivos compartilhados; padrões de } \\
\text { articulação e cooperação entre atores sociais e políticos e arranjos insti- } \\
\text { tucionais que coordenam e regulam transações dentro e pelas fronteiras } \\
\text { do sistema econômico. }\end{array}$ \\
\hline $\begin{array}{l}\text { Sustentabilidade } \\
\text { Bovaird e Löffler (2003, p. 322). }\end{array}$ & $\begin{array}{l}\text { Ações e indicadores de sustentabilidade que compõem o programa e } \\
\text { ações. }\end{array}$ \\
\hline $\begin{array}{l}\text { Respeito pelo Estado de direito } \\
\text { Bovaird e Löffler (2003, p. 322). }\end{array}$ & $\begin{array}{l}\text { A regras que determinam as relações e funcionamento do mercado; inter- } \\
\text { venções corretivas de modo a prover os serviços essenciais. Garantia de } \\
\text { que direitos e obrigações assumidas sejam honradas. }\end{array}$ \\
\hline $\begin{array}{l}\text { Promovida por instituições cen- } \\
\text { trais em assuntos globais } \\
\text { Fayos-Sola, Da Silva e Jafari (2012, } \\
\text { p.17 }\end{array}$ & $\begin{array}{l}\text { Ações promovidas por organismos internacionais, como por exemplo o } \\
\text { Departamento de Assuntos Econômicos e Sociais das Nações Unidas. }\end{array}$ \\
\hline $\begin{array}{l}\text { Enquadradas na área da gestão, } \\
\text { especialmente relacionadas ao } \\
\text { marketing. } \\
\text { Silva e Oom do Valle (2013) }\end{array}$ & $\begin{array}{l}\text { "comportamento do consumidor", "imagem e marca dos destinos" e "go- } \\
\text { vernança e políticas de turismo" foram evidenciadas. }\end{array}$ \\
\hline
\end{tabular}

Fonte: Elaborado pelos autores.

As contribuições dos elementos de boa governança, podem gerar maior eficiência da administração, mais transparência aos stakeholders e ainda possibilitar a participa- ção da população interessada.

No Brasil, foi a partir dos anos 1990 que as concepções de governança e governabilidade ganharam destaque (Ronconi, 
2008). Tal fato deve-se ao País passar a incorporar os ajustes econômicos de corte neoliberal, de ajuste estrutural e de políticas sociais compensatórias e iniciar-se uma reforma do Estado, com o objetivo de redefinir o seu papel (Raquel \& Bellen, 2012). Foi neste período que o Banco Mundial introduziu o conceito de boa governança, como prérequisito para realizar empréstimos aos países em desenvolvimento. Segundo a instituição, a boa governança ocorre quando os governos efetivamente conseguem transformar as suas ações em desenvolvimento socioeconômico para as suas populações. Cabe considerar que, as estratégias e a forma para a boa governança ocorrer, podem variar, sendo o Estado mais ou menos presente, mas mantendo o objetivo de melhores níveis de bem-estar como principal finalidade.

Por outro lado, o World Bank (1992), entende ser possível reconhecer a má governança por alguns sintomas, a saber:

- Deixar de fazer uma separação clara do que é público e o que é privado, ou seja, a frequência de desvios de recursos públicos para ganho privado;

- Falha em estabelecer um comportamento do governo favorável ao desenvolvimento;

- Arbitrariedade na aplicação das regras e das leis;

- Excessiva quantidade de regras, regulamentos, requisitos de licenciamento, que impede o funcionamento dos mercados de forma eficiente;

- Prioridades incompatíveis com o desenvolvimento, resultando na aloca- ção equivocada de recursos.

- Pouca transparência na tomada de decisão.

$\mathrm{Na}$ ocorrência de uma má governança, bons programas e ações podem ser desvirtuados (Miranda, 2012). O interesse pelo emprego da governança no setor público aumentou por causa do novo formato da Administração Pública, que possibilita brechas para o surgimento de fraudes e oportunismo por parte de empresas prestadoras de serviços (Hodges, 1996). Deste modo, percebe-se coerência na aplicação das boas práticas da governança corporativa no setor público, ainda que governos e empresas tenham objetivos diferentes (Osborne \& Gaebler, 1992). Ademais, o ambiente no qual atuam as corporações também é bastante diferente do ambiente político no qual os governos precisam atuar.

As relações de poder que permitem estabelecer a governança não se tratam de relações amistosas, harmônicas, mas de relações que ocorrem em processos conflituosos, o que pode gerar disputas (Dallabrida, 2011), pois se deve buscar a construção de estratégias multiescalares e de governança multinível que contemplem diversas escalas espaciais, articuladas no território alvo do processo de desenvolvimento. Ainda que haja uma transferência de poder, deve-se relativizar esse poder conquistado pela sociedade, pois pode haver limitações no que tange à sua efetividade.

A atividade turística para o Estado inicia-se, por meio das políticas públicas, que, para Barretto, Burgos e Frenkel (2003), o papel das políticas públicas deveria ser o de propiciar o desenvolvimento harmônico 
dessa atividade. Neste sentido, cabe ao Estado construir a infraestrutura de acesso e a infraestrutura básica urbana - que também atende a população local - e prover de uma superestrutura jurídico administrativa (secretarias e similares) cujo papel é planejar e controlar os investimentos que o Estado realiza.

Os efeitos do turismo na economia de uma região podem ocorrer de forma direta, indireta ou induzida (Fundação João Pinheiro [FJP], 2009). Considerando o que se chama de efeitos diretos, estes decorrem de despesas diretamente realizadas pelos turistas em empreendimentos turísticos e outros serviços específicos. Já os efeitos indiretos, resultam de despesas efetuadas por empresas, na aquisição de bens e serviços variados, a fim de viabilizar o turismo. Por fim, o chamado efeito induzido, caracteriza-se por meio do surgimento da circulação financeira, por despesas que são realizadas por quem recebe o recurso financeiro dos prestadores dos serviços turísticos e seus similares (Barreto, Burgos, \& Frenkel, 2003). Destaca-se que a influência que o turismo desenvolve sobre outros setores da economia de uma região permite, em âmbito inter-regional, a negociação, o intercâmbio e a forte influência.

\subsection{Governança do Turismo}

Governança do turismo tem atraído atenção considerável na literatura, fato observado por diversos estudos publicados, em diferentes contextos, pretendendo identificar ou prever as características de uma "boa governança" (Beaumont \& Dredge, 2010; Lockwood, 2010).

No Brasil e em todo o mundo, a lide- rança, seja individual ou institucional, no turismo regional, está ganhando cada vez mais importância. Desde os anos 1990, o Brasil introduziu um leque de políticas sociais, reformas políticas e institucionais para modernizar a sua economia e facilitar o progresso social e econômico (Lohmann \& Dredge, 2012). Novas formas de governança do turismo regional, incorporando parcerias público-privadas, estão sendo introduzidas. A responsabilidade institucional movimenta-se do centro para os níveis regionais e o bastão da liderança tem sido passado do governo nacional para Regional Tourism Organisations - RTOs (Araujo \& Dredge, 2012).

Estudos de gestão de destinos turísticos, atualmente, sugerem que a capacidade de uma organização para implementar estratégias longevas de forma eficaz, envolve partilha de poder, colaboração e acordos conjuntos entre a obtenção de recursos dos setores públicos e privados (Jamal \& Getz, 1999; Bramwell \& Lane, 2011).

Os primeiros trabalhos na governança do turismo, abraçaram a ideia de que poder, competências e recursos, para gerir o turismo, foram distribuídos entre atores públicos, privados e não governamentais, e que governança boa e eficaz é mais provável quando todos os atores trabalham juntos. No contexto destes estudos, os governos não estavam mais sendo vistos de forma separada e independente do setor privado, e burocratas já não eram considerados os únicos árbitros de interesse público ou agentes unilaterais de turismo e das políticas públicas. No entanto, a institucionalização regional prevê barreiras para as partes interessadas locais para integrar nos processos de gestão de destino (Valente, Dredge \& Lohmann, 2015; 
Stoffelen \& Vanneste, 2016).

Mais recentemente, no estudo desenvolvido por Silva e Oom do Valle (2013), que objetivou contribuir para a investigação acerca do Turismo em Portugal, com foco no perfil do investigador e nas características da investigação, as temáticas "comportamento do consumidor", "imagem e marca dos destinos" e "governança e políticas de turismo" foram evidenciadas, enquadradas na área da gestão, especialmente relacionadas ao marketing. Observa-se, assim, uma interdisciplinaridade e diversidade de temáticas pesquisadas envolvendo tais aspectos. Os autores concluem haver um futuro promissor para futuras pesquisa relacionadas ao turismo em Portugal.

A governança é especialmente importante para o turismo, pois é uma atividade transversal complexa, envolvendo grande parte do tecido institucional dos destinos turísticos. Ao contrário do setor agrícola ou comerciais, onde as atividades podem ser circunscritas para produtores e consumidores muito concretos, é quase impossível ter sucesso nos mercados de turismo sem envolver toda a comunidade ou território. Atualmente, a governança é entendida em seu sentido mais amplo como as regras, provisões e operações garantindo a participação proativa de indivíduos nas instituições relevantes e dessas instituições na conceituação do design estratégico, implementação e avaliação de políticas públicas e privadas públicas (Fayos-Sola, Da Silva \& Jafari, 2012).

"O turismo tem sido lento na adoção de formas de governança, mas já existem várias alternativas nesse sentido. Algumas ações têm sido promovidas por instituições centrais em assuntos globais, como o Departamento de Assuntos Econômicos e Sociais das Nações Unidas, por exemplo", afirmam Fayos-Sola, Da Silva e Jafari (2012).

Sendo assim, instituições com finalidade de estrutural a atividade turística como os Circuitos Turísticos passaram a ter maior atenção por parte do poder público de modo a dar condições as regiões de planejarem e desenvolverem os destinos turísticos através destas instâncias de governança crescentes no Brasil.

\subsection{Circuitos Turísticos Brasileiros}

Os circuitos turísticos são responsáveis pela coordenação regional da atividade, contemplando as instâncias de governança regional que participam efetivamente do planejamento do planejamento municipal, haja vista os municípios fazerem parte de um contexto maior que é a região (Brasil, 2009).

Dentre os Circuitos Turísticos brasileiros, destaca-se o da Trilha dos Inconfidentes, em Minas Gerais, por desempenhar um papel de grande relevância no suporte para estruturação dos municípios no planejamento do turismo, razão de ter sido escolhido para este estudo (CTTI, 2010).

Os circuitos reúnem "poder público, iniciativa privada, sociedade civil organizada, podendo abranger organizações da sociedade civil de interesse" (Barbará, Leitão, \& Fontes Filho, 2007, p. 2). Assim, a Política de Regionalização do Turismo é uma realidade consolidada, no cenário do turismo de Minas Gerais, tornando-se necessário avaliar o amadurecimento da gestão dos Circuitos Turísticos, possibilitando traçar novos desafios (Minas Gerais, 2011). 


\section{PROCEDIMENTOS METODOLÓGICOS}

Para que se pudesse atingir os objetivos da pesquisa, utilizou-se a abordagem qualitativa de investigação, haja vista a necessidade de compreender, conforme Richardson (2007), um fenômeno social. A Pesquisa é exploratória “...procura conhecer as características de um fenômeno para procurar explicações das causas e consequências de dito fenômeno" (Richardson, 2007, p. 281). O método utilizado foi o Estudo de Caso (Yin, 2015), estratégia preferível ao se examinarem acontecimentos contemporâneos, uma vez que não se podem manipular os comportamentos relevantes a serem estudados.

A revisão de literatura nacional e internacional foi realizada em livros, periódicos, anais de eventos, jornais e internet, além de dissertações e teses, com a intenção de aprofundar o conhecimento referente ao assunto pesquisado.

Para a coleta de dados foram utilizados dados secundários que permitiram o levantamento de informações econômicas e populacionais sobre os municípios e sobre os órgãos envolvidos com a governança do turismo na região (COMTUR, ASSET, SEBRAE, IPHAN, PREFEITURAS). Posteriormente, realizou-se pesquisa documental em planilhas, projetos desenvolvidos, relação de ações de turismo executadas, cursos e palestras ministrados, convênios, relatórios de gestão e estatutos, consultados nas visitas realizadas às prefeituras e instituições envolvidas no estudo, coletados nas Associações Comerciais, no SEBRAE, na Associação dos Municípios da
Microrregião dos Campos das Vertentes (AMVER) e em outras instituições envolvidas na promoção do turismo das três cidades pesquisadas. Para Gil (2010, p. 121), “... a consulta a fontes documentais é imprescindível em qualquer estudo de caso". Já Yin $(2015$, p.128) aponta que "... para estudos de caso, o uso mais importante dos documentos é para corroborar e aumentar a evidência de outras fontes".

Foram também coletados dados primários, por meio de 12 entrevistas previamente agendadas por e-mail ou telefone, as quais utilizaram o protocolo de um roteiro de perguntas semiestruturado, devidamente validado.

Em estudos de caso, a seleção dos informantes deve considerar "[...] pessoas que estejam articuladas cultural e sensivelmente com o grupo ou organização (Gil, 2010, p.121). Sendo assim, o papel pode ser considerado de um informante, não apenas de um respondente. Yin $(2015$, p. 133) destaca, ainda, que "(...) informantes-chave, são frequentemente fundamentais para o sucesso de um estudo de caso".

\section{RESULTADOS E DISCUSSÃO}

A Tabela 1 apresenta informações sistematizada sobre os atrativos turísticos, número de meios de hospedagem, infraestrutura e faturamento turístico de cada município, tornando possível identificar os elementos favoráveis ao desenvolvimento da atividade turística e à participação do setor no Produto Interno Bruto. 
Tabela 1 - Dados dos municípios pesquisados

\begin{tabular}{l|r|r|r|r|r}
\hline \multicolumn{1}{c}{ Município } & Ext. $\left(\mathbf{K m}^{\mathbf{2}}\right)$ & $\begin{array}{r}\text { No Habit. } \\
\text { Censo 2010 }\end{array}$ & $\begin{array}{c}\text { No Habit. } \\
\text { Estimado 2017 }\end{array}$ & IDH-M & PIB per capita \\
\hline Prados & 264,115 & 8.391 & 9.021 & 0,689 & $13.047,03$ \\
São João Del Rei & $1.452,002$ & 84.469 & 90.263 & 0,758 & $18.334,92$ \\
Tiradentes & 83,047 & 6.961 & 7.807 & 0,740 & $16.500,42$ \\
\hline
\end{tabular}

Fonte: Elaborado pelos autores a partir de IBGE (2017)

Vale ressaltar que os entrevistados selecionados são considerados informanteschave, uma vez que, além de estarem diretamente ligados às decisões relacionadas às atividades turísticas, indicaram possíveis entrevistados e alguns documentos que poderiam contribuir para o cumprimento dos objetivos da pesquisa.

Com base nos elementos destacados por Bovaird e Löffler (2003) e todo o Referencial Teórico, construiu-se o instrumento de coleta de dados e selecionou-se a amostra, que foi constituída intencionalmente por pessoas que pudessem representar as instituições envolvidas com governança nos municípios de Prados, São João Del Rei e Tira- dentes.

Para os dados primários, com base em Reich e Benbasat (1996), foram realizadas 12 entrevistas realizadas entre 2016 e 2017, por meio de roteiro semiestruturado, com atores envolvidos na atividade turística: O poder público, pelos secretários(as) de Turismo, representantes dos Conselhos Municipais de Turismo (COMTUR); Instituições de apoio, como o Serviço Brasileiro de Apoio às Micro e Pequenas Empresas (SEBRAE); Presidentes de Associações Comerciais; Empresários de setores ligados diretamente à atividade turística; Instâncias de Governança, como Instituto Estrada Real (IER) e CTTI.

Quadro 2 - Entrevistados - participantes da pesquisa

\begin{tabular}{|c|l|}
\hline Quantidade & \multicolumn{1}{|c|}{ Representantes } \\
\hline 3 & Secretários Municipais de Turismo (Gestão 2013- 2016) \\
\hline 3 & Representantes de Associações Comerciais de Prados, São João Del Rei e Tiradentes \\
\hline 3 & Empresários do setor de turismo de Prados, São João Del Rei e Tiradentes \\
\hline 2 & $\begin{array}{l}\text { Instituições responsáveis por propor e coordenar ações de desenvolvimento do Turismo nos } \\
\text { municípios (CTTI e IER) }\end{array}$ \\
\hline 1 & $\begin{array}{l}\text { Instituições que fomentam e apoiam as ações e projetos de desenvolvimento do Turismo nos } \\
\text { municípios (SEBRAE) }\end{array}$ \\
\hline
\end{tabular}

Fonte: Elaborado pelos autores

Realizou-se análise documental das políticas públicas, legislações e outros documentos, como projetos, relatórios e convênios de turismo dos municípios para análise dos dados. Optou-se por utilizar a técnica de análise de conteúdo no tratamento dos dados secundários e das entrevistas, a partir de análise categorial que, conforme Caregnato e
Mutti (2006, p. 683), "é o tipo mais antiga e, na prática, a mais utilizada" na análise de conteúdo. Chama-se categorial, pois o texto em análise é desmembrado em categorias, seguindo reagrupamentos analógicos (Bardin, 2004).

Foi utilizado o Software Atlas TI, versão 7, para auxílio na análise de dados das 
entrevistas (Mello, 2006), o que possibilitou gerenciar o conhecimento, por meio da transformação de dados até então soltos em informações úteis, relevantes e flexíveis, de forma sistemática.

\subsection{Apresentação dos resultados}

A região em que se encontram os municípios de Prados, São João Del Rei e Tira- dentes, denominada como mesorregião do Campo das Vertentes (Figura 1), possui uma grande diversidade cultural e forte apelo turístico. São 36 municípios divididos em três microrregiões. Os três municípios em análise têm como característica a arte barroca, a religiosidade, a música, o artesanato e, sobretudo, a riqueza histórica formada pela memória e patrimônio material e imaterial existente nos municípios.

Figura 1 - Mapa da Mesorregião do Campo das Vertentes

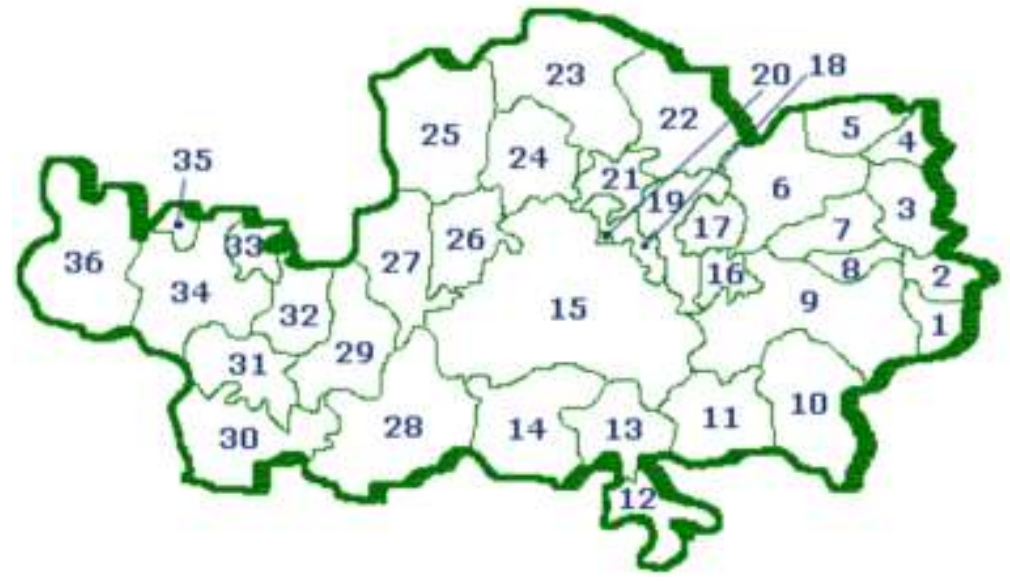

\section{8 - Carrancas \\ 32 - Itumirim \\ 30 - Luminárias}

Microrregião de Lavras

Microrregião de São João Del Rei

26 - Conceição da Barra de Minas

22 - Lagoa Dourada

13 - Piedade do Rio Grande

24 - Ritápolis

15 - São João Del Rei

Microrregião de Barbacena

8 - Alfredo Vasconcelos

16 - Barroso

6 - Carandaí

7 - Ressaquinha

Fonte: Brasilchannel, (1999)
33 - ljaci

29 - Itutinga

36 - Nepomuceno

21 - Coronel Xavier Chaves

14 - Madre de Deus de Minas

19 - Prados

20 - Santa Cruz de Minas

25 - São Tiago

10 - Antônio Carlos

4 - Capela Nova

2 - Desterro do Melo

1 - Santa Bárbara do Tugúrio
31 - Ingaí

34 - Lavras

35 - Ribeirão Vermelho

17 - Dores de Campos

27 - Nazareno

23 - Resende Costa

12 - Santana do Garambéu

18 - Tiradentes

9 - Barbacena

5 - Caranaíba

11 - Ibertioga

3 - Senhora dos Remédios
O CTTI foi fundado no ano de 2000 , no município de Santa Cruz de Minas, constituindo-se enquanto uma entidade civil de direito privado, sem fins lucrativos, gozando de autonomia financeira e administrativa. No entanto, a data de fundação pode ser lida en- quanto parâmetro para legitimar as ações empreendidas pelo Governo do Estado de Minas Gerais a partir da publicação da Lei Estadual no 13.341, em 1999 (Minas Gerais, 1999), a qual estabelece que os governos municipais devam se articular de forma regi- 
onalizada para que o turismo possa ser planejado a partir do pensamento do planejamento turístico participativo. O CTTI foi assim certificado em 18 de maio de 2005 (Setur, 2007; Oliveira \& Fuchs, 2013).

O desenho institucional do CTTI é compreendido a partir da participação social e da gestão participativa, as quais podem ser vislumbradas mediante a leitura e apreciação do Estatuto da Associação do CTTI, assim como do Regimento Interno e do caderno de atas das assembleias deliberativas, instrumentos legais que criam o conjunto de regulamentos internos que visam a organização, administração e funcionamento do CTTI (Oliveira \& Fuchs, 2013).

Um aspecto relevante, no que tange ao processo de certificação é a participação da comunidade durante os processos de desenvolvimento turístico, que representam a divisão das responsabilidades entre os atores locais envolvidos no planejamento (CTTI, 2010).

Atualmente, são 22 municípios asso- ciados ao CTTI, a saber: Alfredo Vasconcelos, Antônio Carlos, Barbacena, Barroso, Carrancas, Conceição da Barra de Minas, Coronel Xavier Chaves, Dores de Campos, Entre Rios de Minas, Ibituruna, Itutinga, Lagoa Dourada, Madre de Deus de Minas, Nazareno, Piedade do Rio Grande, Prados, Resende Costa, Ritápolis, Santa Cruz de Minas, São João Del-Rei, São Tiago e Tiradentes. A sede do circuito está em São João Del Rei. Os municípios que integram este Circuito Turístico evocam tradição e poesia, guardando em seus caminhos e recantos parte significativa da história de Minas Gerais e do Brasil (Oliveira \& Januário, 2007; CTTI, 2010).

\subsection{Governança Regional do Turismo}

Em relação às decisões regionais das ações de turismo que contemplam os municípios, objeto de análise deste estudo, foi possível identificar a seguinte estrutura de decisão:

Figura 2 - Estrutura de decisão regional

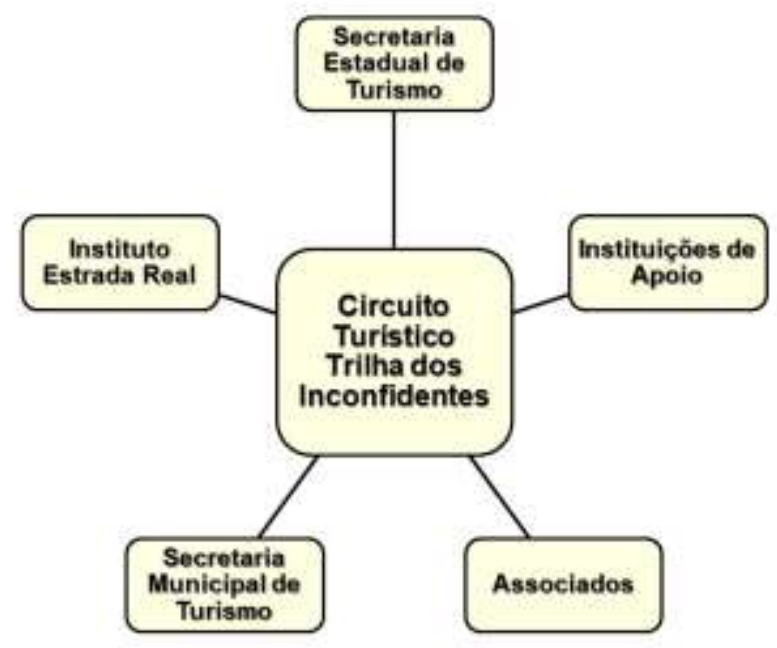

Fonte: Elaborado pelos autores 
O CTTI possui um papel central na integração das atividades relacionadas ao turismo da região. Na estrutura de decisão do turismo regional, o CTTI é protagonista no que diz respeito ao desenvolvimento da atividade turística. A formação da estrutura de decisão é composta pelos Associados do CTTI, ou seja, os municípios que compõem a região e optaram por se associar e participar ativamente do desenvolvimento da atividade turística da região. As Instituições de Apoio, como SEBRAE, SENAC, Instituto do Patrimônio Histórico e Artístico Nacional - IPHAN, dentre outras, na existência de um possível projeto a ser desenvolvido, primeiramente, articulam junto ao CTTI a sua viabilidade e a forma de execução. A Secretaria Estadual de Turismo de Minas Gerais, por meio do Decreto Estadual no 43.321 (2003), art. 1으, para os fins de promoção da política de turismo no âmbito do Estado, reconheceu os Circuitos Turísticos institucionalizados e com personalidade jurídica registrada em cartório, integrados pelos municípios de uma mesma região, com afinidades culturais, sociais e econômicas que se unem para organizar e desenvolver a atividade turística regional de forma sustentável, por integração contínua dos municípios, consolidando uma atividade regional. O Instituto Estrada Real - IER que, para cumprir com seu objetivo de organizar, fomentar e gerenciar o produto turístico Estrada Real, na região do Campo das Vertentes, articula-se com o CTTI no desenvolvimento de suas ações. As Secretarias Municipais de Turismo, na necessidade de planejar, projetar, capacitar ou executar ações de turismo, remetem ao CTTI de modo a buscar auxílio e alinhamento das ações.

Após a gravação das entrevistas, os dados foram transcritos e, posteriormente analisados, com o auxílio da ferramenta Software Atlas TI, versão 7.0. Pelo software foram criadas categorias que, no Atlas $\mathrm{TI}$, são denominadas de "famílias". Estas famílias são resultadas das categorias levantadas no referencial teórico, conforme Bovaird e Löffler (2003).

Após a construção das famílias no Atlas TI, foram criados códigos que se vincularam às famílias, de acordo com o assunto abordado. Vale ressaltar que, "...a ferramenta é um recurso que pode, se bem utilizado, facilitar o gerenciamento dos arquivos, agilizar a codificação e busca de respostas, além de facilitar a comunicação" (Lage \& Godoy, 2008, p. 96).

Foram 12 códigos a partir dos conceitos gerados pelas interpretações dos pesquisadores. Estes foram aplicados, nas transcrições das entrevistas, o que permitiu dividir em temas e trechos específicos que, ao relacionar tais códigos às famílias, permitiu identificar as relações e redes existentes dos dados coletados.

O Quadro 3 apresenta os códigos criados, os vínculos com as famílias e como estas foram relacionadas aos objetivos da pesquisa.

Ao analisar as relações existentes do código 'Igualdade e Inclusão Social', foi possível constatar que parte das ações de igualdade e inclusão social são prioridades, em algumas das ações de turismo, entretanto identificou-se a existência de conflitos entre ambulantes e empresários conforme relato:

Estamos com um problema para resolver a este respeito que são os ambulantes negociando alimentos, calçados e artesanato no centro, em frente às escolas e no Campus Santo Antônio da 
UFSJ. A situação é difícil, porque as lojas pagam todos impostos, alvarás e são muito fiscalizadas e os ambulantes não. Fica uma concorrência desleal. Mas, por outro lado, analisando a questão da inclusão social, é preciso encontrar uma saída boa para os dois lados. Já tem as feiras no final de semana na praça da estação que permitem o artesão expor e vender seus produtos, gerando oportunidade e inclusão. Mas temos casos de oportunistas que utilizam das bancas para vender produtos que não são artesanato, concorrendo com os lojistas. No geral, as ações de turismo promovem, sim, a igualdade, fomentando a atividade do artesão, do santeiro, dos guias (Entrevistado 05).

Quadro 3 - Relação do objetivo, famílias e códigos da pesquisa

\begin{tabular}{|c|c|c|}
\hline OBJETIVO & FAMÍLIAS & CÓDIGOS \\
\hline \multirow{12}{*}{$\begin{array}{l}\text { Verificar o papel e a articulação } \\
\text { dos órgãos de governança nas } \\
\text { ações de turismo desenvolvidas } \\
\text { nos municípios estudados. }\end{array}$} & Agenda de Igualdade e inclusão & Igualdade e Inclusão Social \\
\hline & Sustentabilidade & Ações de Sustentabilidade \\
\hline & Envolvimento dos Cidadãos & Participação da População \\
\hline & Transparência & Transparência de informações \\
\hline & Prestação de contas & Prestação de contas \\
\hline & $\begin{array}{l}\text { Capacidade de competir em um ambiente glo- } \\
\text { bal }\end{array}$ & Competitividade \\
\hline & Comportamento ético e honesto & Responsabilidade e compromisso \\
\hline & $\begin{array}{l}\text { Capital (procedimentos justos e devido pro- } \\
\text { cesso legal) }\end{array}$ & Alocação de recursos \\
\hline & \multirow{2}{*}{$\begin{array}{l}\text { capacidade de trabalhar eficazmente em parce- } \\
\text { ria }\end{array}$} & Parcerias \\
\hline & & Cooperação \\
\hline & Respeito pelo Estado de direito & Garantia de direitos e obrigações \\
\hline & Articulação e Governança das Ações & Articulação e governança das ações \\
\hline
\end{tabular}

Fonte: Elaborado pelos autores

No entendimento do entrevistado, a inclusão social resume-se à oportunidade de trabalho, para que as pessoas possam comercializar os produtos, em feiras e espaços públicos, o que gera um conflito de interesse com empresários locais, que alegam uma concorrência desleal pelo fato de pagarem impostos e recolherem tributos, enquanto os ambulantes não têm a mesma atitude. Tal entendimento é um tanto quanto limitado, quando comparado aos autores Bovaird e Löffler (2003), pois eles entendem que o acesso à moradia, educação e segurança pública são ações que precisam compor a agenda de igualdade e inclusão social na governança da atividade turística.

Em outro relato, referente ao município de Tiradentes, uma percepção relevante corrobora com a atuação do COMTUR na cri- ação de empregos e ocupação direta da população nos eventos turísticos realizados no município, quando o Entrevistado 01 afirma que os eventos absorvem trabalho dos moradores da região nas áreas de limpeza, segurança e atualmente até outras atividades, pois há qualificação realizada pelo SENAC e pelo SEBRAE, inclusive por exigência dos Conselhos, para a questão da segurança.

$\mathrm{Na}$ visão do Entrevistado 03, os grandes eventos, realizados no município, no passado, geravam empregos diretos para a população local apenas em atividades de menor valorização, de baixa complexidade e menor prestígio.

No município de Prados, predomina o entendimento dos entrevistados, quando afirmam que a atividade artesanal é uma forma de inclusão social, sendo uma alterna- 
tiva de renda para as pessoas não têm atividade empregatícia formal, podendo caracterizar-se como socialmente e economicamente inclusivo.

Corroboram com Tomazzoni (2007) dois entrevistados (08 e 09), destacando que a distribuição de renda, como fator de promoção do acesso à educação e saúde, é fundamental para a inclusão social. Neste sentido, a atividade artesanal, desenvolvida nos municípios, compõe a cadeia turística e possibilita a geração e distribuição de renda, proporcionando poder de consumo à população. Além disso, a sustentabilidade social diz respeito à distribuição de renda, e a sustentabilidade cultural que está ligada aos valores, costumes e tradições de uma sociedade, como a atividade artesanal, que, por sua vez, influenciam nos parâmetros de inclusão social (Tomazzoni, 2007).

Santos e Silva (2015) conceituam os trabalhos artesanais como valores, práticas, costumes e culturas elaboradas por diferentes grupos familiares, com marcas que identificam a região.

$\mathrm{Na}$ análise do código 'Ações de Sustentabilidade', algumas dificuldades foram apontadas pelos entrevistados, como o fato de não existir uma diretriz norteadora para a promoção de ações do turismo e sim ações de sustentabilidade pontuais. No município de São João Del Rei, uma ação apontada por três dos entrevistados foi o Projeto de Agroturismo Colônia Viva, realizado em parceria entre SESI, SEBRAE, Secretaria Municipal de Turismo e CTTI, valoriza o trabalho de agroturismo dos descendentes italianos que vieram para a cidade. $\mathrm{O}$ roteiro turístico conta com visitação e degustação do que é produ- zido nessa colônia. Este projeto vem ganhando visibilidade tanto para os entrevistados quanto para a população da região e turistas. Programas vinculados em rede de televisão, em âmbito nacional, foram produzidos retratando as características do agroturismo Colônia Viva, como a preservação da tradição local, a agricultura familiar, o uso sustentável e a conservação da diversidade biológica brasileira.

Quanto à percepção de empresários de Tiradentes, referentes a ações de sustentabilidade ambiental, informações coletadas afirmam que o prefeito tentou implantar a coleta seletiva, mas não houve sucesso, pois não há a cultura de se proceder desta forma, ou seja, não houve educação ambiental que permitisse o sucesso dessa ação. Assim, a intenção do gestor público foi boa, mas a estratégia de execução foi equivocada e incompleta.

Conforme as falas dos entrevistados, algumas iniciativas e ações de sustentabilidade são realizadas, entretanto, precisam ser melhor estruturadas para que se almeje resultados mais expressivos. No município de Prados, apontaram a atividade artesanal como exemplo de ações de sustentabilidade a partir do próprio artesanato local, um produto sustentável, pois muitas das peças produzidas têm como matéria-prima produtos recicláveis e/ou reciclados. Os produtos artesanais e as pinturas surgem do aproveitamento do ferro e da madeira de demolição, além de latas, plásticos, tecidos de algodão, palha e outros recursos naturais.

Tendo o código 'Participação da população' como referência, aspectos relacionados a tomada de decisões foram aponta- 
dos pelos entrevistados de Prados, que a população participa por meio de associações, como a Associação de Empresários, Associação de Artesãos, embora algumas vezes a população não seja consultada sobre decisões tomadas. O SEBRAE oferece cursos de capacitação para empresários, principalmente artesãos, mas normalmente são ofertados cursos já formatados, sem que haja pesquisa junto aos empresários para verificar demanda específica.

Neste caso, vale ressaltar que, no processo de planejamento, seja de uma política pública, seja um programa ou projeto, a participação dos executores é tão relevante quanto a participação dos que serão diretamente atingidos pelas ações. Tal fato já era apontado por Paixão (2003), ao afirmar que a governança pressupõe que questões diretamente relacionadas, como no caso de cursos para os empresários, a participação nos processos de decisórios por parte da sociedade é crucial.

Observou-se que as instituições e os mecanismos de representação que participam das decisões, nem sempre cumprem o papel de defender os desejos da população. A participação da população, em decisões significativas, é apontada por Bovaird e Löffler (2003), ao destacar o elemento 'Envolvimento dos cidadãos' como um dos pressupostos para a governança.

No município de Tiradentes, a participação se dá pelos representantes do COMTUR, por onde passam todas as decisões. Essa atuação se destaca dos demais municípios em termos de organização, eficiência e eficácia nas demandas por ele atendidas. 0 COMTUR é a forma de participação da popu- lação em paridade com o poder público, que não pode ter uma representatividade maior do que a população.

No município de São João Del Rei, apesar de existirem as associações de classes, foram apontados alguns questionamentos quanto à sua efetiva representação nas decisões de interesse coletivo. O Entrevistado 05 afirmou que a participação da população ocorre por meio das associações de bairros, de artesãos, de bares e restaurantes, de hotéis e pousadas. 0 Entrevistado 06 corroborou ao afirmar sentir falta de maior integração com a população, e com empresários, na definição de prioridades, sendo que quando sabem sobre algum projeto, às vezes, é quando este já está em execução, uma grave falha na comunicação.

Conforme visto na revisão teórica, para conseguir o envolvimento da população com a atividade turística, são necessárias ações que envolvam, despertem e, sobretudo, sinalizem a aprovação para o exercício da atividade. O estabelecimento de condições que promovam a realização do potencial das capacidades e faculdades da mente humana, em pessoas e comunidades, é um dos entendimentos para que se consiga o desenvolvimento (Pike et al., 2007).

Quanto ao código 'Transparência de Informações', no município de Tiradentes identificou-se a necessidade desse quesito ser melhor trabalhado, até por não ser uma responsabilidade só de prefeitura e sim de todos os envolvidos. O Entrevistado 03 afirmou a necessidade de se evitar roubo ou margem para a não contribuição para desvios, ou seja, há carência de transparência nas informações. Pode-se observar na fala a 
existência de uma certa consciência de que a responsabilidade deve ser compartilhada. A articulação e comunicação das metas, ações, papéis e responsabilidades são algumas das práticas necessárias para o desenvolvimento da atividade turística (Valente et al., 2015).

Nos municípios de Prados e São João Del Rei, foram apontadas nas entrevistas afirmações sobre haver transparência das informações, entretanto, cabe destacar certa confusão dos entrevistados quanto ao entendimento do conceito de transparência e o conceito de prestação de contas. Em alguns casos, o entrevistado afirmava que havia transparência das ações, mas foi possível perceber que, o que de fato há, é a prestação de contas para os membros da instância de governança.

Referente ao código 'Prestação de Contas', foi constatado a existência desta, entretanto, o baixo envolvimento e participação em reuniões e assembleias seja nas associações comerciais e instâncias de governança, como o COMTUR, alguns empresários afirmam não haver uma prestação de contas adotando modelos profissionais, conforme previstos por Bovaird e Löffler (2003), mas depois constatou-se que tais afirmações se deram por desconhecimento e falta de participação por parte de alguns empresários.

No que se refere ao código 'Competitividade', no município de São João Del Rei, destaca-se o patrimônio artístico e cultural da cidade, que apresenta um conjunto arquitetônico com casas no estilo barroco, pontes, igrejas, museus, utensílios e móveis. Além disso, o município dispõe de patrimônio imaterial, que precisa de "muito empenho para não se perder" (Entrevistado 09). Trata-se da produção cultural, da memória coletiva local, da linguagem dos sinos, dos rituais religiosos, sobretudo na semana santa, somados à musicalidade - características únicas de São João Del Rei, muito importante que sejam consideradas.

Apesar de um rico patrimônio material e imaterial, é destacado que a divulgação das atividades e localidades turísticas de São João Del Rei, se comparada a de Tiradentes, é muito "atrasada". O calendário de eventos, que é de responsabilidade do COMTUR, por vezes, coincide com outros eventos de cidades vizinhas, como é o caso de Tiradentes, que possui um calendário mais consolidado.

Quanto ao município de Prados, a produção artesanal é apontada como diferencial competitivo. As esculturas de animais em madeira e peças decorativas têm enorme visibilidade, sendo premiadas em feiras de artesanato. Além disso, há outros produtos artesanais como fuxicos, crochês, tapetes, esculturas, móveis, bordados, telas e pinturas, artefatos que impulsionam a economia e o desenvolvimento regional.

Observa-se que os atrativos existentes nos municípios são complementares, o que em virtude da proximidade entre as cidades, possibilita uma diversidade de produtos, serviços e atrativos turísticos.

Referente a análise do código 'Responsabilidade e Compromisso' existente entre os agentes promovedores do turismo na região, relatos apontam o desinteresse de empresários em investir em São João Del Rei, o que prejudica as ações e projetos propostos pela prefeitura e parceiros. Algumas capacitações não recebem envolvimento da população, pois em vários casos há baixa adesão. Há a percepção de que os empresários não acreditam nos projetos de turismo, não havendo empenho para o desenvolvi- 
mento do turismo.

É possível perceber nas falas dos entrevistados que, em virtude de alguns projetos ou ações malsucedidas, o poder público é responsabilizado e fica desacreditado quanto às propostas para desenvolver o turismo no município, enquanto o empresário é visto como pouco participativo do processo.

Por sua vez, no município de Tiradentes, destaca-se a atuação do COMTUR, tida como referência, denotando responsabilidade e compromisso dos atores envolvidos, sendo que recebe até mesmo pessoas do SEBRAE, interessadas em conhecer mais sobre essa forte atuação.

Já no município de Prados, a percepção dos entrevistados vinculados ao setor empresarial, é de que esperam maior atuação do Poder Público, que não se mostra tão empenhado.

No que se refere ao código 'Alocação de Recursos', ficou evidenciada a participação da população nas decisões quanto à alocação de recursos, que ocorre por meio da representatividade nos Conselhos Municipais de Turismo dos municípios. Como em Tiradentes o COMTUR é tido como mais atuante, a percepção é de que exista maior participação na definição de alocação dos recursos turísticos na esfera de decisão deste município.

Quando analisado o código 'Parcerias', constatou-se que no município de São João Del Rei, existem diversas, especialmente com instituições de apoio do Estado, como SEBRAE, SENAC, IPHAN, IER, Associações entre outras. Tais parcerias são essenciais para o turismo e para o desenvolvimento regional. Há, adicionalmente, parcerias com a $\mathrm{ACl}, \mathrm{CTTI}$, Conselho Municipal de Patrimônio, Associação Regional de Produtores Associados do Campo das Vertentes - ARPA, Secretaria de Obras, Associação de Guias, Representantes de Museus, Igrejas, o que gera interessante network, que pode impulsionar o desenvolvimento de outros dos projetos.

No município de Prados, os entrevistados destacaram que as parcerias necessitam ser melhor trabalhadas, especialmente porque não há muita cooperação entre os diversos atores. Por sua vez, em Tiradentes, destacou-se um maior envolvimento entre os atores para com as atividades, gerando parcerias interinstitucionais. Entretanto, conforme relatos dos entrevistados, ainda precisam ser melhoradas. Foi destacada a possibilidade de parcerias com instituições de ensino, onde há muitos jovens que precisam ser conscientizados sobre a importância desses eventos para o desenvolvimento da região.

Com relação ao código 'Cooperação', foi possível constatar a existência desta nas ações de marketing de turismo regional entre os três municípios estudados com outros da região. No entanto, conforme relato do Entrevistado 08, referente ao município de Prados, há certo individualismo no que se refere a capacitações, pois empresários querem ser capacitados, mas não querem que seus concorrentes o sejam.

$\mathrm{Na}$ análise do código 'Garantia de Direitos e Obrigações', quando perguntado aos entrevistados se os direitos e obrigações eram cumpridos nos contratos, convênios, acordos, todos os entrevistados afirmaram que sim, ressaltando, em alguns casos, dificuldades na finalização de algum convênio, 
mas cumprindo o que havia sido acordado.

Ao finalizar a análise do último código

'Articulação e Governança das Ações', foram identificadas várias situações de conflito e problemas de governança nas ações de turismo nos três municípios.

Referente a atuação do IER nos projetos desenvolvidos na região, observou-se um descrédito por parte de alguns dos entrevistados quanto o atual desempenho da instituição na promoção do turismo. Em contrapartida, verificou-se que o IER se encontra com algumas dificuldades jurídicas que o impede temporariamente de atuar em diversas frentes as quais atuava no desenvolvimento do turismo em Minas Gerais.

Situações apontadas pelos entrevistados como problemas de governança, referem-se a falta de sincronia entre as instituições na promoção de ações de desenvolvimento do turismo na região, como por exemplo, capacitações semelhantes sendo ofertadas por instituições distintas. Ressalta-se que quando se fala em governança, esta vai muito além do gerenciamento e tem um amplo alcance, quando estabelece estruturas capazes de lidar com a cultura, a organização e a direção das instituições (Barret, 2003).
Foram identificados, ainda, problemas de governança referentes ao fortalecimento das instâncias do turismo. Conforme Dallabrida e Becker (2008), a gestão territorial, a partir de estruturas de governança, possui uma direta relação com a ampliação da prática democrática. Desenvolver a atividade turística sobre tais preceitos resultará numa maior responsabilização da sociedade com seu futuro e maior exercício da cidadania. O progresso permanente da região e de cada indivíduo pertencente a ela é um processo de mudança social sustentada que caracteriza o Desenvolvimento Regional.

Foi possível observar que o CTTI está presente entre as instituições e instâncias de decisão dos três municípios analisados, sendo apontado como a instância de maior influência no turismo regional. Tal constatação foi feita, a partir dos relatos das entrevistas, documentos consultados, como estatutos dos Conselhos Municipais de Turismo em que o CTTI possui representatividade e relevante participação, Lei Estadual no 13.341 (2000), artigos científicos sobre o tema, dentre outras fontes (Oliveira \& Januário, 2007; Setur, 2007; CTTI, 2010; Oliveira \& Fuchs, 2013):

Quadro 4 - Instituições que exercem Poder e Capital Social

\begin{tabular}{|c|c|c|}
\hline Elemento & Município & Instituições \\
\hline \multirow{4}{*}{$\begin{array}{c}\text { Poder e } \\
\text { Capital } \\
\text { Social }\end{array}$} & Prados & Secretaria Municipal de Turismo e Cultura / COMTUR / CTTI \\
\hline & Tiradentes & Secretaria Municipal de Turismo e Cultura / COMTUR / CTTI / ASSET \\
\hline & São João Del Rei & Secretaria Municipal de Cultura, Turismo, Esporte e Lazer /COMTUR /CTTI /ACI \\
\hline & Região & CTTI / Secretaria Estadual de Turismo / IER \\
\hline
\end{tabular}

Fonte: Elaborado pelos autores

A gestão sistêmica do turismo no Campo das Vertentes é comandada pelo CTTI. A coordenação das ações, o desenvolvi- mento do ambiente cultural favorável à comunicação e cooperação, sendo que há prefeitos participando internamente no CTTI. 
Conforme Tomazzoni (2007), a existência de coordenação regional centralizadora e articuladora, para implementação de planos, a articulação e organização das entidades responsáveis pela gestão do turismo são aspectos essenciais na gestão sistêmica do turismo, papel este que nos três municípios analisados e na região do Campo das Vertentes vem sendo exercido pelo CTTI.

Valente et al. (2015) já apontavam que a articulação e comunicação de metas e ações e, também, a articulação de papéis e responsabilidades são algumas das práticas necessárias para o desenvolvimento do turismo regional. Neste sentido, a capacidade de realizar atividades, independentemente do poder de comando do governo ou do uso de sua autoridade, demonstra elementos favoráveis à governança e considera, nesta circunstância, que o governo é capaz de utilizar novas ferramentas e técnicas para governar (Stoker,1998).

Quanto à divulgação mais regional, restrito ao Campo das Vertentes, o CTTI desenvolve tal função, mas sem desvincular da imagem da Estrada Real. Tanto é que, em vários eventos e feiras, são estabelecidas parcerias para que, tanto a marca Estrada Real, quanto a marca do CTTI, sejam divulgadas de forma conjunta.

Além de divulgação, o CTTI desenvolve um importante papel de articulação entre os municípios, tanto no planejamento das ações, quanto na definição de calendário de eventos, viabilização financeira, suporte na elaboração de políticas e planos de turismo, dentre outros.

Verificou-se que a articulação e go- vernança das ações desenvolvidas nos municípios se dá a partir do CTTI, que possui relevante poder e influência sobre as ações, projetos e programas realizados nos municípios e, ainda, é responsável por estabelecer um canal direto com o poder público na esfera estadual e federal em prol de necessidades da região. As ações são planejadas, considerando os contextos regional e local, buscando integrar instituições de apoio à atividade turística, fortalecendo e responsabilizando os Conselhos Municipais de Turismo na tomada de decisão e estabelecimento de diretrizes e prioridades na condução da atividade.

Foi constatado que o papel da governança no Desenvolvimento Regional, a partir do turismo na região do Campo das Vertentes, possibilitou maior entendimento dos municípios quanto à interdependência entre eles na consolidação da região como um destino turístico diversificado, com atrativos variados e complementariedades de produtos e serviços que agregam valor para as pessoas que desejam visitar a região e promove o desenvolvimento da comunidade.

Pode-se concluir que a região vem se destacando como um exemplo de governança, para o Desenvolvimento Regional por meio do turismo, e os resultados vêm influenciando o modo como empresários, população e poder público dos municípios planejam essa atividade. Neste sentido, o CTTI possui papel central na articulação, integração, estruturação e fortalecimento do turismo, fazendo da governança regional da atividade turística um caso de Desenvolvimento Regional. 


\section{CONSIDERAÇÕES FINAIS}

Foi possível constatar a existência de diferenças significativas, tanto analisando em nível municipal e regional, quanto entre instituições que exercem maior influência e poder sobre as decisões de turismo na região. Em Tiradentes, observou-se que o COMTUR e a Associação Empresarial de Tiradentes - Asset, possuem grande influência sobre as decisões do turismo desenvolvido no município, inclusive, o prefeito municipal da gestão 2013-2016 abriu precedente para que o COMTUR definisse um profissional técnico para assumir a Secretária Municipal de Turismo.

Em São João Del Rei, a Secretaria Municipal de Cultura, Turismo, Esporte e Lazer possui maior influência sobre as ações de turismo desenvolvidas no município, seguida pela $\mathrm{ACl}$ e pelo COMTUR que apresenta dificuldades para se consolidar como instância de decisão. Em Prados, a Secretaria de Turismo e Cultura, também possui maior relevância nas decisões referente ao Turismo, mas o COMTUR demonstra-se, atuante e cada vez mais, significativo nas decisões. A participação da Associação Comercial é quase inexistente, conforme relatos dos entrevistados.

Já, em nível regional, conforme relatos das entrevistas e dados coletados, identificou-se o CTTI como a principal instância de governança e articulação do turismo na região. O IER já teve um papel mais relevante no fortalecimento do turismo na região, entretanto, em virtude de problemas estruturais, judiciais e políticos, atualmente, não desenvolve um papel de protagonista para o turismo na região.
Outras instituições como SEBRAE, Secretaria Estadual de Turismo, IPHAN, Associações, também, participam do processo de Desenvolvimento Regional, a partir do turismo na região, entretanto o CTTI representa o elo entre agentes municipais, como poder público e iniciativa privada e, ainda, em instâncias do poder público estadual e federal, juntamente com outras instituições fomentadoras do turismo.

Assim, a articulação e a governança do turismo regional do Campo das Vertentes ocorrem por meio do CTTI, responsável pelo papel mais relevante neste processo. Notase que disputas políticas existentes na região comprometem a integração dos municípios pois, existindo partidos opositores uns aos outros, ocupando o poder nos municípios no mesmo período, as ações conjuntas e de integração na região exigem maior habilidade política do CTTI a fim de mediar as articulações e demonstrar que o desenvolvimento regional está acima de disputas político partidárias.

Finalizando, registre-se que esta pesquisa contribui para o entendimento de fatores que relacionam governança como elemento de proteção e planejamento do turismo regional integrado, sob a ótica de indutores de desenvolvimento. Reconhece-se a limitação da pesquisa por tratar-se de um estudo de caso e, por essa razão, seus resultados não poderem ser generalizados para outras localidades e/ou regiões. Ainda assim, sugere-se para pesquisas futuras a oportunidade de comparar os achados desta pesquisa com a temática da governança e do desenvolvimento regional a partir do turismo e do artesanato em outras regiões do País, ou do exterior. 


\section{AGRADECIMENTOS}

Os autores agradecem a Universidade Municipal de São Caetano do Sul e Instituto Federal de Educação, Ciência e Tecnologia do Sul de Minas Gerais.

\section{REFERÊNCIAS}

Alcade, E. A., Bourlegat, C. A. L, \& de Castilho, M. A. (2007). O papel dos agentes na comunidade de artesãos em Três Lagoas-MS, como instrumentos impulsionadores do desenvolvimento local. Revista Internacional de Desenvolvimento Local, 8(2), 223-234.

Araujo, L. M. \& Dredge, D. (2012). Tourism development, policy and planning in Brazil, in Lohmann, G. and Dredge, D. (Eds), Tourism in Brazil: Environment, Management and Segments, (pp. 17-29). Routledge, New York.

Barbará, S., da Silva Leitão, M. C., \& Fontes Filho, J. R. (2007). A governança regional em turismo: realidade? Estudo de caso sobre o destino Estrada Real. Cadernos EBAPE. BR, 5(4).

Bardin, L. (2004). Análise de conteúdo. Lisboa: edições.

Barret, P. (2003). Achieving Better Practice Corporate Governance in the Public Sector. AM Auditor General for Australia. Disponível em: <http://www.anao.gov.au/uploads/documents>. Acesso em: 23 nov. 2015.

Barretto, M., Burgos, R., \& Frenkel, D. (2003). Turismo, políticas públicas e relações internacionais. Papirus Editora.

Bassan, D. S. \& Siedenberg, D. R. (2008). Desenvolver buscando a redução das desigualdades. In: Becker, D. F. \& Wittmann, M. L. Desenvolvimento regional: abordagens interdisciplinares. Santa Cruz do Sul: EDUNISC,

Beaumont, N., \& Dredge, D. (2010). Local tourism governance: A comparison of three network ap- proaches. Journal of Sustainable Tourism, 18(1), 7-28.

Boisier, S. (2009). Em busca do esquivo desenvolvimento regional: entre a caixa-preta e o projeto político. Planejamento e políticas públicas, (13).

Bovaird, T., \& Löffler, E. (2003). Evaluating the quality of public governance: indicators, models and methodologies. International Review of Administrative Sciences, 69(3), 313-328.

Bramwell, B., \& Lane, B. (2011). Critical research on the governance of tourism and sustainability. Journal of Sustainable Tourism, 19(4-5), 411421.

Brasil (2009). Ministério do Turismo. Coordenação Geral de Regionalização. Programa de Regionalização do Turismo - Roteiros do Brasil: Introdução à Regionalização do Turismo. Secretaria Nacional de Políticas Públicas de Turismo. Brasília, 2009. Disponível em: <http://www.turismo.gov.br/images/progra-

mas_acoes_home/PROGRAMA_DE_REGIONALIZACAO_DO_TURISMO_-_DIRETRIZES.pdf>

Acesso em: 29 dez. 2015.

Brasil (2007a). Ministério do Turismo. Plano Nacional de Turismo 2007-2010. Brasília, 2007-a. Disponível em: <http://www.turismo.gov.br/turismo/o_ministerio/plano_nacional/ebook/index.html> Acesso em: 28 dez. 2015.

Brida, J. G., Riaño, E., Devesa, M. J. S., \& ZapataAguirre, S. (2012). Valoración del turismo de cruceros por parte de la comunidad local: Cartagena de Indias. Revista electrónica de Geografía y Ciencias Sociales, Scripta Nova. 16(1).

Caregnato, R. C. A., \& Mutti, R. (2006). Pesquisa qualitativa: análise de discurso versus análise de conteúdo. Texto \& contexto - Enfermagem, 15(4), 679-84.

Carniello, M. F., \& dos Santos, M. J. (2013). Comunicação e desenvolvimento regional. Revista brasileira de gestão e desenvolvimento regional, 9(2), 325-345. 
Circuito Turístico Trilha dos Inconfidentes (2010). O que é um circuito turístico? Disponível em: $<$ http://www.trilhadosinconfidentes.tur.br/institucional.php>. Acesso em: 22 dez. 2015.

Cunha, S. K., \& Cunha, J. C. (2005). Modelo sistêmico para avaliação do impacto do turismo no desenvolvimento local. Anais do Encontro Nacional dos Programas de Pós-Graduação em Administração - EnANPAD, 29, Brasília, DF, Brasil.

Dallabrida, V. R. (2011). Governança territorial e desenvolvimento: as experiências de descentralização político-administrativa no Brasil como exemplos de institucionalização de novas escalas territoriais de governança. Instituto de Pesquisas Econômicas Apicadas (Ipea). Code. Disponível em: https://www.unc.br/mestrado/textos/ARTIGO-IPEA-GOVERNANCA-TERRITORIAL-e-DESENVOLVIMENTO-VALDIR.pdf. Recuperado em: 02 de jan. 2016.

Dallabrida, V. R. \& Becker, D. (2008). Dinâmica territorial do desenvolvimento. In: Becker, D.; Wittmann, M. Desenvolvimento regional: abordagens interdisciplinares. Santa Cruz do Sul: Edunisc. 8(1).

Dreher, M. T. \& Salini, T. S. (2010). Governança e Políticas Públicas de Turismo em Gaspar, Santa Catarina. Anais de Seminário de Pesquisa em Turismo do MERCOSUL - SeminTUR. 6. Caxias do Sul, $\mathrm{RS}$, Brasil.

Fayos-Sola, E., Da Silva, J. A. M., \& Jafari, J. (2012). Knowledge Management in Tourism: Policy and Governance Applications: Emerald Group Publishing.

Fundação João Pinheiro - FJP (2009). Impacto do Turismo nas Finanças Municipais nas Regiões Turísticas do Brasil. Belo Horizonte: Centro de Estudos de Políticas Públicas.

Gil, A. C. (2010). Como elaborar projetos de pesquisa. 5 ed. São Paulo: Atlas.

Gil, A. C., Oliva, E. C., \& Silva, E. C. (2009). Turismo e regionalidade. Turismo-Visão e Ação, 11(1), 92111.
Girard, L. F., \& Nijkamp, P. (2009). Narrow escapes: pathways to sustainable. Local cultural tourism. Cultural tourism and sustainable local development, 1-9.

Gomes, B. M. A. (2006). Política de regionalização do turismo em Minas Gerais: uma análise sob a ótica dos custos de transação. Lavras: UFLA.

Hodges, R., Wright, M., \& Keasey, K. (1996). Corporate governance in the public services: Concepts and issues. Public Money \& Management, 16(2), 7-13.

International Federation of Accountants - IFAC (2001). Governance in the Public Sector: A Governing Body Perspective International Public Sector-Study, 13.

Jamal, T., \& Getz, D. (1999). Community roundtables for tourism-related conflicts: The dialectics of consensus and process structures. Journal of Sustainable Tourism, 7(3-4), 290-313.

Lage, M. C., \& Godoy, A. S. (2008). O uso do computador na análise de dados qualitativos: questões emergentes. Revista de Administração Mackenzie (Mackenzie Management Review), 9(4).

Lockwood, M. (2010). Good governance for terrestrial protected areas: A framework, principles and performance outcomes. Journal of environmental management, 91(3), 754-766.

Lohmann, G., \& Dredge, D. (Eds.). (2012). Tourism in Brazil: Environment, management and segments. Routledge.

Mello, R. B. (2006). Pesquisa qualitativa em estudos organizacionais: paradigmas, estratégias $e$ métodos. Softwares em pesquisa qualitativa. São Paulo: Saraiva.

Miranda, R. A. (2012) Governança: um índice para unidades federativas brasileiras. (Tese de doutorado) Faculdade de Ciências Econômicas. Centro de Pós-Graduação e Pesquisa em Administração. Universidade federal de Minas Gerais. Belo Horizonte, MG, Brasil. 
Minas Gerais (2011). Diretrizes da Política Pública de Turismo de Minas Gerais. Belo Horizonte: Secretaria de Estado de Turismo. Disponível em:< http://www.turismo.mg.gov.br/images/stories/diretrizes-da-politica-publica-de-turismo-vs2-2030.pdf>. Acesso em: 18 nov. 2016.

Minas Gerais (2015). O turismo mineiro em números. Belo Horizonte: Secretaria de Estado de Turismo. Belo Horizonte, MG, Brasil.

(2014). Orientações para o planejamento e gestão municipal do turismo em Minas Gerais. Secretaria de Estado de Turismo. Belo Horizonte, MG, Brasil.

Molina, S. (2005). Fundamentos del nuevo turismo de la fase industrial a la innovación. México: Trillas.

Neves, R., \& Carneiro, E. J. (2014). Empreendedorismo e marketing urbano: a mercadorização do centro "histórico" de Tiradentes, Minas Gerais, na ótica do turismo. Revista Cenário, 2(2), 65-81.

Oliveira, F. F. D., \& Fuchs, A. M. S. L. (2013). O planejamento turístico participativo na gestão do Circuito Turístico Trilha dos Inconfidentes/MG. NAU Social, 4(6), 100-119.

Oliveira, S. T., \& Januário, M. V. C. (2007). O Turismo em São João Del Rei Minas Gerais: Uma Análise Preliminar. CULTUR: Revista de Cultura e Turismo, 1(1), 1-10.

Osborne, D., \& Gaebler, T. (1992). Reinventing government: How the entrepreneurial spirit is transforming government. Reading Mass. Adison Wesley Public Comp. 21(1).

Paixão, L. M. (2013). Arranjos produtivos locais, governança territorial e desenvolvimento turístico no meio rural: o caso das regiões turísticas da Serra Gaúcha, Bonito e Treze Tílias. (Dissertação de mestrado) Programa de Pós-Graduação em Desenvolvimento Regional e Urbano) - Universidade de Salvador. Salvador, BA, Brasil.

Pereira, C. A. S. (1999). A Trajetória da política de turismo em Minas Gerais e o papel do poder le- gislativo em sua transformação (Dissertação de mestrado) Programa de Pós-Graduação em Ciência Política. Universidade Federal de Minas Gerais, Belo Horizonte, MG, Brasil.

Pereira, J. M. (2010). Governança no setor público. São Paulo: Editora Atlas.

Pike, A., Rodríguez-Pose, A., \& Tomaney, J. (2007). What kind of local and regional development and for whom? Regional studies, 41(9), 1253-1269.

Raquel, I., \& Bellen, H. M. V. (2012). Contribuição à Concepção da Governança Pública: Uma Análise a partir da Visão dos Especialistas. Anais do Encontro Nacional dos Programas de Pós-Graduação em Administração - EnANPAD, 36, Rio de Janeiro, RJ, Brasil.

Richardson, R. J. (2007). Pesquisa social: métodos e técnicas. 3. ed. São Paulo: Atlas.

Rodrigues, L. M.; Silva, M. N. S.; Diniz, R. F. (2012). Artesanato mineiro: limites e possibilidades da atividade artesã no município histórico de Prados/MG. Revista Eletrônica de Geografia, 4(11), 62-85.

Ronconi, L. F. D. A. (2008). A Secretaria Nacional de Economia Solidária: uma experiência de governança pública. (Tese de doutorado). Centro de Filosofia e Ciências Humanas. Programa de PósGraduação em Sociologia Política. Universidade Federal de Santa Catarina. Florianópolis, SC, Brasil.

Santos, J. C. V., \& Silva, J. A. (2015). A arte da olaria no turismo da região Algarve, Portugal. Revista Turismo - Visão e Ação, 17(3), 658-690.

(2016). Arte popular criativa e turismo cultural na cidade de Loulé (Algarve/Portugal). Revista Brasileira de Pesquisa em Turismo, 10(2), 212-232.

Santos, T. S., Souza, P. A. R., \& Pereira, R. S. (2014). Pesquisa em turismo e desenvolvimento regional: análise dos estudos realizadas no Brasil entre os anos de 1997 e 2013. Anais de Seminá- 
rios em Administração. 17. São Paulo, SP, Brasil.

Secretaria de Estado do Turismo de Mg - SETUR. (2007) Circuitos turísticos. Disponível em < http://www.turismo.mg.gov.br/circuitos_turisticos.php>. Acesso em 02 jan. 2018.

Shone, M. C., \& Ali Memon, P. (2008). Tourism, public policy and regional development: A turn from neo-liberalism to the new regionalism. Local Economy, 23(4), 290-304.

Silva, G. A. B., \& Passador, J. L. (2016). Redistribuição fiscal para o desenvolvimento turístico local e regional. Revista de Administração Pública, 50(4), 587-610.

Silva, J. A.; Oom do Valle, P. (2013). A investigação em turismo em Portugal: um contributo para a sua caracterização. Revista Brasileira de Pesquisa em Turismo, 7(3). Disponível em: $<$ http://www.redalyc.org/arti-

culo.oa id $=504152259003>$. Acesso em: 28 mar. 2018.

Silveira, G. T. (2008). Turismo, emprego e renda: o caso da cidade histórica de Tiradentes - MG. (Dissertação de mestrado) Programa de Pós-Graduação em Turismo) - Universidade de Caxias do Sul. Caxias do Sul, RS, Brasil.

Sousa, B. M. (2016). A dinâmica diferenciadora e o processo de criação na gestão de destinos turísticos. Revista Brasileira de Pesquisa em Turismo, 10(1), 3-17.

Souza, L. H., Pena, L. C. S., \& Moesch, M. M. (2017). Conhecimento e sinergia como indutores da inovação regional em turismo: o caso do Observatório do Turismo no Distrito Federal (Brasil). Revista Brasileira de Pesquisa em Turismo, 11(1), 19-38.

Souza, P. A. R., Andrade, F. A.V, \& Wolff Cordeiro, K. (2012). Os impactos da organização do ambiente institucional no desenvolvimento do arranjo produtivo local do município de Parintins na Amazonia. Revista de Turismo y Patrimonio Cultural, 10(5).
Stoffelen, A., \& Vanneste, D. (2016). Institutional (dis) integration and regional development implications of whisky tourism in Speyside, Scotland. Scandinavian Journal of Hospitality and Tourism, 16(1), 42-60.

Stoker, G. (1998). Governance as theory: five propositions. International social science journal, 50(155), 17-28.

Tomazzoni, E. L. (2007). Turismo e desenvolvimento regional: modelo APL TUR aplicado à região das Hortênsias (Rio Grande do Sul-Brasil). (Tese de doutorado) - Escola de Comunicações e Artes, Universidade de São Paulo. São Paulo, SP, Brasil.

Valente, F., Dredge, D., \& Lohmann, G. (2015). Leadership and governance in regional tourism. Journal of Destination Marketing \& Management, 4(2), 127-136.

Wahab, S. (1991). Introdução a administração do turismo: (alguns aspectos estruturais e operacionais do turismo internacional): teoria e prática. São Paulo: Pioneira.

Widmer, G. M., \& Pires, M. J. (2008). A Convenção do Patrimônio Mundial, Cultural e Natural, como possível elemento indutor de atividade turística. Revista Hospitalidade, 5(2), 52-64.

World Bank (1992). Governance and Development. Washington - DC: BIRD.

World Travel \& Tourism Council - WTTC (2016). Annual report - 2016: The Economic Advantages of Travel e Tourism. Disponivel em: <https://www.wttc.org/-/media/files/reports/economic\%20impact\%20research/regions\%202016/world2016.pdf>. Acesso em: 04 fev. 2018.

Yin, R. K. (2015). Estudo de Caso: Planejamento e Métodos. Porto Alegre: Bookman editora. 


\section{Informação dos autores}

\section{Thiago de Sousa Santos}

Bacharel em Administração pela Universidade Federal de São João Del Rei (UFSJ). Mestre em Administração, área: Gestão Estratégica, Marketing e Inovação, pela Universidade Federal de Lavras (UFLA). Doutor em Administração, área: Gestão para o Desenvolvimento Regional, pela Universidade de São Caetano do Sul (USCS). Experiência em gestão de empresas e consultoria, gerenciamento de projetos, empreendedorismo e Micro e Pequena Empresa (MPEs) com várias premiações no período que atuou no SEBRAE. Foi coordenador do Curso Superior de Tecnologia em Gestão Comercial e do Curso Técnico em Administração do IFSULDEMINAS. É professor efetivo na mesma instituição atuando principalmente nos seguintes temas: Gestão Estratégica, Desenvolvimento Regional, Turismo, Empreendedorismo e Marketing. Também é pesquisador do Grupo de Pesquisa Gestão para o Desenvolvimento Sustentável GDS/USCS e Grupo de Estudos em Redes, Estratégia e Inovação GEREI/UFLA.

E-mail: thiago.santos@ifsuldeminas.edu.br ORCID: https://orcid.org/0000-0002-5589-0595

\section{Raquel da Silva Pereira}

Doutora em Ciências Sociais (2003) e Mestre em Administração (1999), ambos pela PUC/SP. Especialista em Administração de Recursos Humanos, pela Escola Superior de Administração de Negócios - ESAN (1988) e Licenciada Plena por meio do Curso de Formação de Professores (ESQUEMA I) pela Faculdade de Tecnologia de São Paulo - FATEC/SP (1992). Bacharel em Administração de Empresas, pela Universidade São Judas Tadeu - USJT (1984). Desde março de 2008 atua como professora na graduação da Universidade Municipal de São Caetano do Sul (IMES/USCS). É professora e pesquisadora do Programa de Pós-graduação em Administração (PPGA/USCS), no qual foi Gestora durante o período entre maio de 2011 e julho de 2014 e novamente é Gestora desde janeiro de 2016. Implantou e coordenou o Curso de Bacharelado em Administração, no SENAC/SP (abril/2007 a março/2008). Atuou como Diretora de Educação Continuada (julho a dezembro/2006), área de pós-graduação lato sensu, com 60 cursos, na Uninove. Foi Diretora de Departamento Acadêmico (julho/2000 a julho/2006), dirigindo os Cursos de Administração (Geral e Habilitações); Ciências Econômicas; Ciências Contábeis: Secretariado Executivo e Turismo. Coordenou cursos de Administração (Geral e Habilitações) entre janeiro/1999 e setembro/2000, na Uninove. Criou e formatou os primeiros Cursos Superiores de Formação Específicas (Sequenciais) do Brasil, os quais coordenou por mais de um ano. Atua como docente desde 1989 e pesquisa sobre Desenvolvimento Sustentável, Responsabilidade Social, Desenvolvimento Regional, Gestão Ambiental, Sustentabilidade Socioambiental, Gestão de Pessoas e sobre Gestão no Ensino Superior. É fundadora e líder do Grupo de Pesquisa CNPq denominado GDS - Gestão para o Desenvolvimento Sustentável. Possui experiência de mercado na área administrativa, tendo atuado em organizações como Banco Itaú S/A, Perdigão Alimentos S/A e Banco Mercantil de São Paulo, dentre outras. Desenvolve conteúdos de disciplinas a serem ministrados a distância. É autora de livros, capítulos de livros e artigos nacionais e internacionais. Possui projetos de pesquisa aprovados pela CAPES, pela FAPESP e pelo CNPq. É avaliadora de processos submetidos à CAPES.

E-mail: raquel.pereira@prof.uscs.edu.br ORCID: http://orcid.org/0000-0001-6656-080X 